\title{
Temperatura e umidade relativa na qualidade da tangerina "Montenegrina” armazenada
}

\author{
Temperature and relative humidity during cold storage of 'Montenegrina' tangerine
}

\author{
Auri Brackmann' ${ }^{\mathrm{I}}$ Miguel Edevaldo Peterle ${ }^{\mathrm{II}}$ Josuel Alfredo Vilela Pinto ${ }^{\text {III }}$ \\ Anderson Weber ${ }^{I I}$ Cláudia Kaehler Sautter ${ }^{\text {III }}$ Ana Cristina Eisermann ${ }^{\text {II }}$
}

\section{RESUMO}

O presente trabalho foi conduzido com o objetivo de avaliar o efeito da temperatura e da umidade relativa do ar (UR) sobre a manutenção da qualidade de tangerinas durante $o$ período de armazenamento refrigerado (AR). O delineamento experimental utilizado foi inteiramente casualizado, em esquema bifatorial, com oito repetições, contendo 15 frutos cada. Os tratamentos avaliados constituíram-se da combinação das temperaturas 2, 3 e $4^{\circ} \mathrm{C}$, com UR do ar de 90 e 96\%. Após oito e 12 semanas de armazenamento, mais três dias de exposição a $20^{\circ} \mathrm{C}$, foram realizadas as seguintes análises: acidez total titulável (ATT), sólidos solúveis totais (SST), consistência dos frutos, incidência de podridões e suculência. De acordo com os resultados obtidos, os frutos armazenados a $3^{\circ} \mathrm{C}+U R$ do ar de $90 \%$ apresentaram ATT, SST e consistência mais elevada, após oito e 12 semanas de AR. A incidência de podridão foi significativamente superior nos tratamentos com alta UR do ar (96\%). Injúrias provocadas pela baixa temperatura ocorreram em alguns frutos no tratamento a $2^{\circ} \mathrm{C}$. Não se constatou diferença significativa na suculência entre os tratamentos em ambas as datas de avaliação. A temperatura de $3^{\circ} \mathrm{C}$ combinada com UR de $90 \%$ apresentou os melhores resultados na conservação de tangerinas "Montenegrina”, que podem ser armazenadas por um período de até oito semanas.

Palavra-chave: refrigeração, conservação, Citrus deliciosa.

\section{ABSTRACT}

This research was conducted in order to evaluate the effect of temperature and relative humidity $(\mathrm{RH})$ on the quality of tangerines during cold storage. The experimental design was entirely randomized, in a bifatorial design with eight replications of 15 fruits. The treatments were the combination of three temperatures $\left(2,3\right.$ and $\left.4^{\circ} \mathrm{C}\right)$ and two $\mathrm{RH}$ levels (90 and 96\%). Evaluations of quality were performed after 8 and 12 weeks of cold storage plus 3 days of shelf life at $20^{\circ} \mathrm{C}$. The analyzed parameters were: total titratable acidity (TTA), total soluble solids (TSS), fruits consistency, rot incidence and juiciness. According to the results, fruits stored at $3{ }^{\circ} \mathrm{C}+$ 90\% of RH presented higher TTA, TSS, fruits consistency and lower rot incidence after 8 and 12 weeks of cold storage. The rot incidence increased with high $\mathrm{RH}$ (96\%). Some pitting caused by low temperature was found at $2^{\circ} \mathrm{C}$. There was no difference between treatments for juiciness in both evaluations. The temperature of $3^{\circ} \mathrm{C}$ with $90 \%$ of $\mathrm{RH}$ showed the best results on quality maintenance of 'Montenegrina' tangerines, which can be stored during 8 weeks.

Key words: cold, conservation, Citrus deliciosa.

\section{INTRODUÇÃO}

O Brasil é o maior produtor mundial de frutas cítricas, sendo as tangerinas o segundo grupo de cítricos mais produzidos. Cerca de 1,16 milhões de toneladas de tangerinas são colhidas anualmente no país (IBGE, 2004). Com uma área plantada de 13.195 hectares, o Rio Grande do Sul é o segundo maior produtor desta fruta (IBGE, 2004). Entre as cultivares, a tangerina "Montenegrina" ocupa a terça parte da área plantada com tangerineiras no Estado, destacando-se as plantações do vale dos rios Caí e Taquari (KOLLER, 1994). Além disso, observa-se um expressivo aumento da área de produção na serra gaúcha e na região do Alto Uruguai (BOLETIM FEPAGRO, 2005).

A tangerineira "Montenegrina" é uma cultivar tardia, cujos frutos possuem sabor e aroma agradáveis, de grande aceitação pelo consumidor, além

\footnotetext{
'Departamento de Fitotecnia, Universidade Federal de Santa Maria (UFSM), 97105-900, Santa Maria, RS, Brasil. E-mail: brackman@ccr.ufsm.br. Autor para correspondência.

"Curso de Agronomia, CCR, UFSM, Santa Maria, RS, Brasil.

"IIPrograma de Pós-graduação em Agronomia, UFSM, Santa Maria, RS, Brasil.
} 
de outras características desejáveis para um fruto cítrico de mesa, tais como polpa firme, fácil descascamento e boa conservação (BRACKMANN et al., 1999a).

$\mathrm{O}$ armazenamento refrigerado (AR) é a alternativa utilizada para prolongar o período de oferta dos frutos cítricos na entressafra quando se obtém uma valorização de até $100 \%$ do produto (PEREIRA et al. 1989). Outra alternativa para a comercialização na entressafra é a colheita tardia, porém, esta prática provoca um esgotamento da planta, originando uma alternância de produção. O AR reduz a desidratação e a ocorrência de podridões, mas pode causar distúrbios fisiológicos. As frutas cítricas demonstram sensibilidade a baixas temperaturas, que se manifesta por meio da morte de células da casca (“pitting”), da formação de manchas circulares e deprimidas de coloração marrom e de alterações do sabor (PORAT et al., 2004). A intensidade do dano varia com a temperatura de armazenamento e com o período de exposição (KLUGE et al., 2006). No entanto, temperaturas muito altas provocam maior atividade respiratória e, conseqüentemente, perda de firmeza e alta incidência de podridões.

O controle da umidade relativa (UR) do ar no interior da câmara é um fator importante para a conservação das frutas durante o AR. Os níveis de UR do ar só podem ser comparados nas mesmas condições de temperatura. Por esta razão, há necessidade de um controle associado à temperatura de armazenamento (CHITARRA \& CHITARRA, 1990). A manutenção da UR do ar na faixa ideal diminui a desidratação dos tecidos, afeta a interação patógeno-fruto e diminui os danos provocados pela baixa temperatura (BRACKMANN et al., 1999a). Níveis de UR do ar abaixo dos requeridos promovem perda da aparência fresca dos frutos. Em geral, a perda de água é tanto maior quanto mais longo o período de conservação, mais elevada a temperatura e mais baixa a UR do ar. Por outro lado, UR do ar próximas da saturação (98 a 100\%) podem ocasionar o desenvolvimento excessivo de microorganismos patogênicos (CHITARRA \& CHITARRA, 1990).

Tangerinas "Montenegrina” podem ser armazenadas por um período de até quatro semanas em temperaturas de 3 a $5^{\circ} \mathrm{C}$, associadas com 90 a $97 \%$ de UR do ar (BRACKMANN et al.,1999a). Para BELLOTO (1989), este período pode ser prolongado por até nove semanas, em 3 a $4^{\circ} \mathrm{C}$, com 85 a 90\% de UR do ar. HARDENBURG (1986) e CHOEN (1993) afirmam que tangerinas, em geral, devem ser armazenadas a $4^{\circ} \mathrm{C}$, com UR de $90 \%$, por um período de duas a quatro semanas, sendo que nas temperaturas de 0 e $1^{\circ} \mathrm{C}$ ocorrem danos causados pelo frio. A tangerina
"Satsuma” pode ser armazenada por seis semanas em temperatura de $2^{\circ} \mathrm{C}$ e UR do ar de 93\% (ARTÉS et al., 1995).

Nota-se certa divergência dos autores entre a melhor temperatura e UR do ar para o armazenamento de tangerinas. Assim, o objetivo deste trabalho foi determinar as condições de UR do ar e a temperatura mais adequada para a manutenção da qualidade de tangerinas “Montenegrina”, durante o armazenamento refrigerado.

\section{MATERIAL E MÉTODOS}

O experimento foi conduzido no Núcleo de Pesquisa em Pós-Colheita (NPP) do Departamento de Fitotecnia da Universidade Federal de Santa Maria (UFSM), no período de outubro a dezembro de 2005. Para o experimento, foram utilizados frutos provenientes de um pomar comercial localizado no município de Cotiporã, Rio Grande do Sul.

Após a chegada dos frutos ao NPP, os mesmos foram selecionados, descartando-se os frutos lesionados e/ou com baixo calibre $(<55 \mathrm{~mm})$. Depois disso, as amostras experimentais foram homogeneizadas e colocadas em redes plásticas para o armazenamento em câmaras frigoríficas. Em seguida, foi efetuada a análise inicial de uma amostra com 15 frutos e quatro repetições. Os frutos apresentavam 11,1 graus Brix de sólidos solúveis totais e 1,28g de ácido cítrico $100 \mathrm{~mL}^{-1}$ de acidez total titulável. Não foi realizado nenhum tratamento com fungicida póscolheita. O delineamento experimental utilizado foi o inteiramente casualizado, em esquema bifatorial, no qual os fatores estudados foram diferentes temperaturas e UR do ar. Cada tratamento foi constituído por oito repetições, contendo 15 frutos cada. Os regimes de armazenamento se constituíram das seguintes combinações entre temperaturas e níveis de UR do ar: $1-2^{\circ} \mathrm{C}+90 \%$ de UR; $2-2^{\circ} \mathrm{C}+96 \%$ de UR; $3-3^{\circ} \mathrm{C}+90 \%$ de UR; $4-3^{\circ} \mathrm{C}+96 \%$ de UR; 5 $4^{\circ} \mathrm{C}+90 \%$ de UR e $6-4^{\circ} \mathrm{C}+96 \%$ de UR. A temperatura e a UR do ar foram monitoradas diariamente durante todo o período de armazenamento. Para reduzir a UR do ar a $90 \%$, foi utilizada uma solução de cloreto de cálcio com capacidade higroscópica, como meio absorvente. Para aumentar a UR do ar, a minicâmara foi umidificada quando necessário.

As análises laboratoriais foram realizadas após oito e 12 semanas de armazenamento, mais três dias de exposição dos frutos a $20^{\circ} \mathrm{C}$. Os parâmetros analisados foram: acidez total titulável (ATT) determinada pela titulação de $10 \mathrm{ml}$ de suco diluídos em 100ml de água destilada, com uma solução de $\mathrm{NaOH}$ 
$(0,1 \mathrm{~N})$, até atingir $\mathrm{pH} 8,1$, sendo os resultados expressos em gramas de ácido cítrico $100 \mathrm{~mL}^{-1}$; Sólidos solúveis totais (SST) - determinados por refratometria, a partir do suco extraído dos frutos, com compensação do efeito da temperatura e expressos em graus Brix; Incidência de podridões - obtida pela contagem dos frutos que apresentavam lesões com diâmetro superior a 5,0mm e com características típicas de ataques de fungos; Suculência - determinada pela prensagem de aproximadamente $20 \mathrm{~g}$ de gomos retirados aleatoriamente do fruto. A pesagem foi efetuada antes e depois dos mesmos serem submetidos à extração do suco, pelo método de prensagem desenvolvido no NPP/ UFSM, conforme descrito por LUNARDI et al. (2004), através de um pistão pneumático ligado a um compressor de $12 \mathrm{kgf} \mathrm{cm}^{-2}$ pressionado contra uma plataforma de 1,5 toneladas por 60 segundos; Consistência dos frutos - avaliados subjetivamente através de aperto dos frutos com as mãos, em que nível 1 = fruto firme; nível 2 = fruto pouco firme e nível 3 = fruto mole. O índice de consistência foi obtido pela média de cinco avaliadores, sendo que o índice obtido, por cada avaliador, é resultado da soma dos totais da multiplicação do número de frutos pelo seu respectivo nível e dividido pelo total de frutos. Quanto maior o valor do índice de consistência, mais mole é o fruto, significando pior qualidade.

Os dados expressos em porcentagem foram transformados pela fórmula arc.sen $\sqrt{\mathrm{x} / 100}$ antes de serem submetidos, junto com os demais, à análise de variância. As médias foram comparadas entre si pelo teste de Tukey em nível de 5\% de probabilidade.

\section{RESULTADOS E DISCUSSÃO}

De acordo com os quadros da análise de variância (Tabelas 1 e 2), não houve interação significativa entre os fatores temperatura e UR do ar para os parâmetros analisados após oito e 12 semanas de armazenamento refrigerado.

O conteúdo de ácidos orgânicos nas frutas, em geral, aumenta durante os primeiros estádios de desenvolvimento e decresce lentamente durante a maturação e o armazenamento. Valores mais altos de ATT são sinônimos de qualidade (BRACKMANN et al., 1999b). Após oito semanas de AR os frutos armazenados a $3^{\circ} \mathrm{C}+90 \%$ de UR do ar apresentaram maiores valores de ATT (Tabela 1), provavelmente, devido à concentração dos ácidos orgânicos em função da perda de peso e menor atividade respiratória (BRACKMANN et al., 1999a). Após 12 semanas de $A R$, verificou-se um maior decréscimo da acidez titulável quando associada com alta UR do ar e alta temperatura (Tabela 1). Essa diminuição pode estar relacionada com a própria senescência do fruto, considerando a maior incidência de podridões nos mesmos e que os ácidos podem servir de substrato para a respiração (KLUGE, 2006). No entanto, os frutos armazenados a $2^{\circ} \mathrm{C}$ também apresentaram valores baixos da ATT. Este fato deve-se provavelmente à ocorrência de injúrias provocadas pela baixa temperatura, causando o consumo dos ácidos orgânicos por enzimas oxidativas (SALA, 1998). Resultados semelhantes foram obtidos em trabalhos citados por KOLLER (1994), em que tangerinas armazenadas em várias temperaturas perderam a acidez continuamente durante as oito semanas de armazenamento.

Os SST são compostos solúveis em água e importantes na determinação da qualidade da fruta. $\mathrm{O}$ teor de SST indica a quantidade de açúcares existentes na fruta, além de compostos como ácidos, vitaminas, aminoácidos e algumas pectinas (CHITARRA \& CHITARRA, 1990). Após oito semanas de armazenamento, os SST se mantiveram mais elevados nos frutos armazenados a $3^{\circ} \mathrm{C}$, não havendo diferença estatística entre as UR do ar de 90 e 96\% (Tabela 1). No entanto, após 12 semanas, houve diferença estatística, sendo que a $90 \%$ de UR do ar os frutos apresentaram níveis superiores de SST. Alguns autores associam o aumento do SST com a desidratação dos frutos e a concentração dos açúcares. No entanto, de acordo com ECHEVERRIA \& ISMAIL (1990), o aumento dos SST, após a colheita, é resultado de atividades biológicas, admitindo-se como hipóteses a conversão de ácidos orgânicos em glicolíticos intermediários e subseqüentemente a hexoses ou a liberação de açúcares solúveis por outros glicolíticos como a hidrólise do amido, uma vez que a perda da água em frutas cítricas se restringe em maior parte à epiderme, mantendo constante o rendimento de suco durante o armazenamento.

Com relação à suculência, após oito semanas, os frutos armazenados em $90 \%$ de UR do ar apresentaram valores mais baixos quando comparados aos expostos a UR do ar de 96\% (Tabela 2). Entretanto, após 12 semanas de AR, não se verificou diferença significativa em relação a este parâmetro independente da condição de armazenamento utilizada (Tabela 2).

Um dos principais motivos que geralmente impede longos períodos de armazenamento e comercialização dos frutos de consumo "in natura” é a incidência de podridões. $\mathrm{O}$ armazenamento dos frutos a $90 \%$ de UR do ar proporcionou os menores percentuais de podridões na saída da câmara e após três dias de exposição a $20^{\circ} \mathrm{C}$ (Tabela 2). Ao se comparar esse resultado nas mesmas condições de temperaturas com UR do ar de 96\%, observa-se um grande benefício 
Tabela 1 - Qualidade físico-química de tangerina 'Montenegrina' após oito e doze semanas de armazenamento refrigerado, mais três dias de exposição a $20^{\circ} \mathrm{C}$. Santa Maria, RS, 2007.

\begin{tabular}{|c|c|c|c|c|c|c|c|c|c|}
\hline \multicolumn{10}{|c|}{ Oito semanas de armazenamento } \\
\hline Tratamentos & \multicolumn{3}{|c|}{$\begin{array}{c}\text { Acidez titulável } \\
\text { (g de ácido cítrico } 100 \mathrm{~mL}^{-1} \text { ) }\end{array}$} & \multicolumn{3}{|c|}{ SST (graus Brix) } & \multicolumn{3}{|c|}{ Suculência (\%) } \\
\hline \multirow{2}{*}{$\begin{array}{l}\text { Temperatura } \\
\left({ }^{\circ} \mathrm{C}\right)\end{array}$} & \multicolumn{2}{|c|}{-------UR (\%)-------- } & \multirow{2}{*}{ Média } & \multicolumn{2}{|c|}{--------UR (\%)-------- } & \multirow{2}{*}{ Média } & \multicolumn{2}{|c|}{----------UR (\%)---------- } & \multirow{2}{*}{ Média } \\
\hline & 90 & 96 & & 90 & 96 & & 90 & 96 & \\
\hline 2 & 1,15 & 1,11 & $1,13 \mathrm{~b}^{1}$ & 11,9 & 11,8 & $11,8 \mathrm{~b}$ & 78,6 & 79,5 & $79,0 \mathrm{a}$ \\
\hline 3 & 1,23 & 1,13 & $1,18 \mathrm{a}$ & 12,6 & 12,1 & $12,4 \mathrm{a}$ & 78,5 & 79,3 & $78,9 \mathrm{a}$ \\
\hline 4 & 1,13 & 1,10 & $1,12 \mathrm{~b}$ & 12,1 & 11,9 & $12,0 \mathrm{ab}$ & 78,2 & 79,3 & $78,7 \mathrm{a}$ \\
\hline Médias & $1,17 \mathrm{~A}$ & $1,11 \mathrm{~B}$ & & $12,2 \mathrm{~A}$ & $12,0 \mathrm{~A}$ & & $78,4 \mathrm{~B}$ & 79,4 & \\
\hline CV (\%) & & 5,3 & & & 4,4 & & & 1,5 & \\
\hline \multicolumn{10}{|c|}{ Doze semanas de armazenamento } \\
\hline 2 & 1,10 & 1,07 & $1,08 \mathrm{~b}$ & 11,8 & 11,5 & $11,6 \mathrm{~b}$ & 80,0 & 80,1 & $80,0 \mathrm{a}$ \\
\hline 3 & 1,20 & 1,11 & $1,16 \mathrm{a}$ & 12,4 & 12,0 & $12,2 \mathrm{a}$ & 79,8 & 80,6 & 80,2 a \\
\hline 4 & 1,08 & 1,03 & $1,06 \mathrm{~b}$ & 12,1 & 11,4 & $11,7 \mathrm{~b}$ & 78,7 & 80,9 & $79,8 \mathrm{a}$ \\
\hline Médias & $1,13 \mathrm{~A}$ & $1,07 \mathrm{~B}$ & & $12,1 \mathrm{~A}$ & $11,6 \mathrm{~B}$ & & $79,5 \mathrm{~A}$ & $80,5 \mathrm{~A}$ & \\
\hline CV (\%) & & 11,9 & & & 3,6 & & & 6,1 & \\
\hline
\end{tabular}

Análise físico-química realizada na instalação do experimento: acidez titulável de 1,28g de ácido cítrico $100 \mathrm{~mL}^{-1}$, SST de $11,1{ }^{\circ}$ Brix.

${ }^{1}$ Médias não seguidas da mesma letra, nas colunas, diferem entre si ao nível de 5\% de probabilidade de erro pelo teste de Tukey.

na redução da UR do ar para 90\% na redução da incidência de podridões. ARTÉS et al. (1995) afirmam que com a diminuição da UR do ar há também um decréscimo do ataque de fungos, embora altos níveis de
UR do ar possam diminuir a incidência de alguns danos como puffness (casca solta) e enrugamento da casca.

Uma das causas da alta incidência de podridões é a colheita de tangerinas com pedúnculo e

Tabela 2 - Incidência de podridões e índice de consistência de tangerinas “Montenegrina” após oito e doze semanas de armazenam£nto refrigerado, mais três dias de exposição a $20^{\circ} \mathrm{C}$. Santa Maria, RS, 2007.

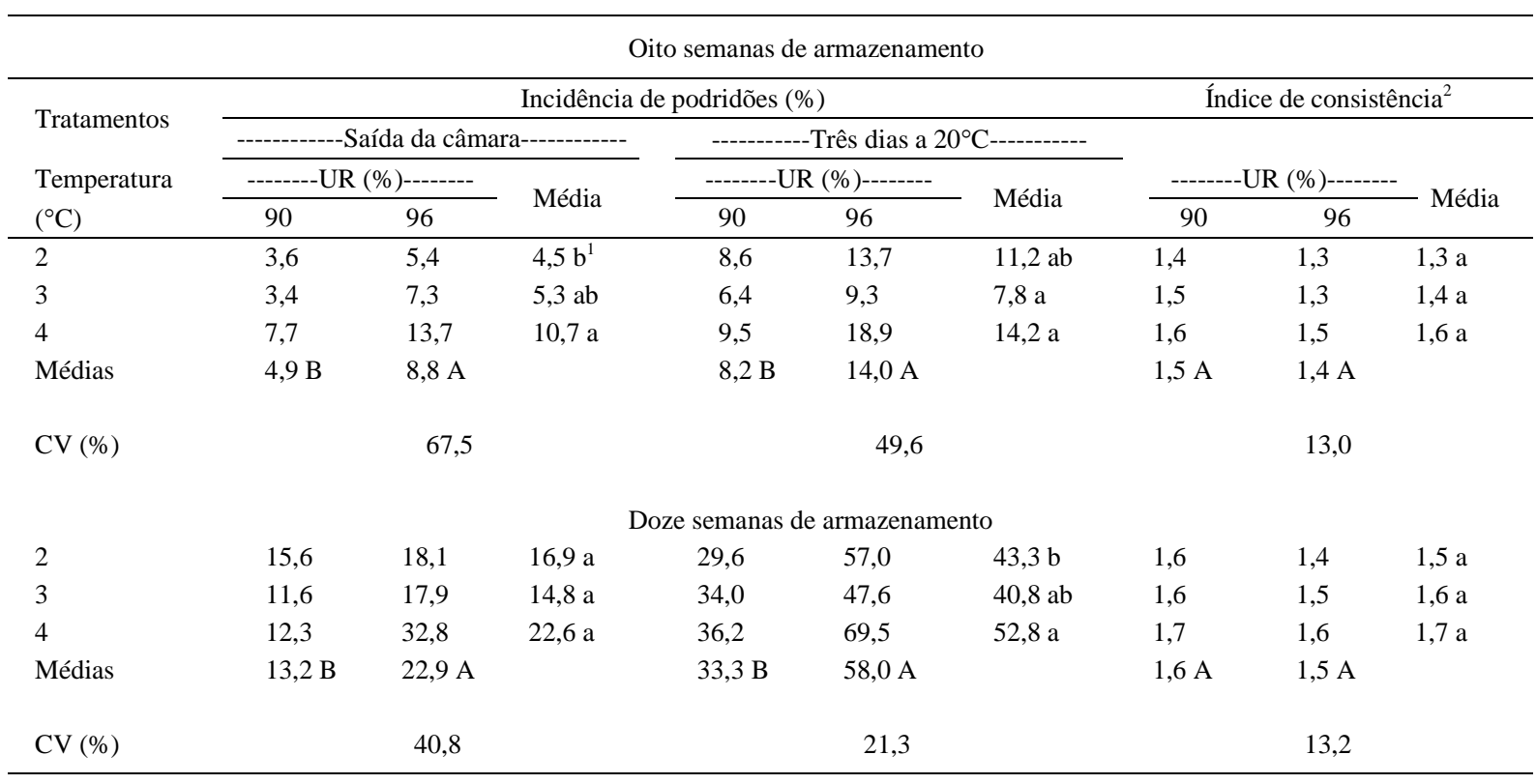

Análise físico-química realizada na instalação do experimento: índice de consistência de 1,0.

${ }^{1}$ Médias não seguidas da mesma letra, nas colunas, diferem entre si em nível de $5 \%$ de probabilidade de erro pelo teste de Tukey.

${ }^{2}$ Níveis de consistência dos frutos: nível 1 - fruto firme; nível 2 - fruto pouco firme e nível 3 - fruto mole.

Ciência Rural, v.38, n.2, mar-abr, 2008. 
folhas, prática muito utilizada no sul do Brasil. Segundo o BOLETIM FEPAGRO (2005), esta prática deveria ser abolida, pois o pedúnculo pode perfurar os outros frutos e favorecer a entrada de patógenos, além disso, as folhas podem servir como meio de transmissão de doenças. Sugerimos, para futuros trabalhos, a avaliação da colheita de tratamentos com fungicida antes e/ou após a colheita para o controle das perdas por podridões em tangerinas.

Após oito e 12 semanas de AR, não houve diferença significativa entre os tratamentos para ambos os parâmetros analisados (temperatura e umidade relativa do ar) em relação ao índice de consistência dos frutos (Tabela 1). Os frutos armazenados em 90\% de UR do ar e alta temperatura $\left(4^{\circ} \mathrm{C}\right)$ apresentaram menor consistência, em ambas as datas avaliadas, provavelmente em função de uma maior perda de água da epiderme e conseqüente perda do turgor. Embora o armazenamento dos frutos a 96\% de UR do ar tenha proporcionado maior consistência, estes apresentaram maior incidência de podridão, provocando grandes perdas de frutos.

\section{CONCLUSÕES}

Dentre as temperaturas e UR do ar avaliadas, a melhor temperatura de armazenamento para a tangerina "Montenegrina” é de $3^{\circ} \mathrm{C}$ e a UR do ar é $90 \%$, sendo que em $96 \%$ de UR aumenta a ocorrência de podridões. A tangerina "Montenegrina” pode ser armazenada por oito semanas sem grandes perdas, já após 12 semanas podem ocorrer perdas significativas devido a podridões.

\section{REFERÊNCIAS}

ARTÉS, F. et al. Influence of fungicide treatment and storage conditions on mould and yeast activity on 'Satsuma' mandarin. International Journal of Refrigeration. v.18 n.1, p.6366, 1995.

BELOTTO, F.A. et al. Influência de sistemas de embalagens e tratamentos com fungicidas sobre a frigoconservação de tangerinas "Montenegrina” (Citrus deliciosa Tenore). In: CONGRESSO BRASILEIRO DE FRUTICULTURA, 10., 1989, Fortaleza. Anais... Fortaleza: Sociedade Brasileira de Fruticultura, 1989. p.144-148.

BOLETIM TÉCNICO FEPAGRO. O cultivo dos citros no Rio Grande do Sul: referências tecnológicas. Porto Alegre: FEPAGRO, 2005. N.16, 141p.

BRACKMANN, A. et al. Armazenamento refrigerado de tangerinas (Citrus reticulata Blanco) cv. "Montenegrina”. Revista Científica Rural, v.4, n.2, p.38-42, 1999a.

BRACKMANN, A. et al. Frigoconservação e controle de podridões em laranja "Valência”. Ciência Rural, v.29, n.2, p.247-251, 1999b.

CHITARRA, M.I.F.; CHITARRA, A.B. Pós-colheita de frutos e hortaliças: fisiologia e manuseio. Lavras: ESAL-FAEPE, 1990. 293p.

CHOEN, E. et al. Storage temperature, duration and wax coating on the keeping quality of Nova mandarin. London: Postharvest News and Information, 1993. V.4, n.4, 198p.

ECHEVERRIA, E.; ISMAIL, M. Sugar unrelated to brix changes in stored citrus fruits. HortScience, v.25, n.6, p.710, 1990

FIORAVANÇO, J.C.; MÂNICA, I. Armazenamento de frutas cítricas em temperatura controlada. Cadernos de Horticultura, v.2, n.2, p.1-8, 1994.

HARDENBURG, R.E. et al. The commercial storage of fruits, vegetable, florist and nursery stocks. Washington: U.S. Department of Agriculture, 1986. 136p. (Agriculture Handbook, n.66)

IBGE - Produção agrícola municipal: culturas temporárias e permanentes. Rio de Janeiro, 2004. V.31, 133p.

JOMORI, M.L.L. et al. Conservação refrigerada de lima ácida 'Tahiti': uso de 1-metilciclopropeno, ácido giberélico e cera. Revista Brasileira de Fruticultura, v.25, n.3, p.406-409, 2003.

KLUGE, R.A. et al. Efeitos de tratamentos térmicos aplicados sobre frutas cítricas armazenadas sob refrigeração. Ciência Rural, v.36, n.5, p.1388-1396, 2006.

KOLLER, O.C. Citricultura: laranja, limão e tangerina. Porto Alegre: Rígel, 1994. 246p.

LUNARDI, R. et al. Suculência e solubilização de pectinas em maças “Gala” armazenadas em atmosfera controlada, em dois níveis de umidade relativa. Ciência Rural, v.34, n.3, p.743747, 2004.

PEREIRA, R.G. et al. Estudo sobre a viabilidade econômica da frigoconservação de tangerinas "Montenegrina" (Citrus deliciosa Tenore). In: CONGRESSO BRASILEIRO DE FRUTICULTURA, 10., 1989, Fortaleza. Anais... Fortaleza: Sociedade Brasileira de Fruticultura, 1989. p.136-139.

PORAT, R. et al. Reduction of postharvest rind disorders in citrus fruit by modified atmosphere packaging. Postharvest Biology and Technology, v.33, n.1, p.35-43, 2004.

SALA, M.J. Involvement of oxidative stress in chilling injury in cold-stored mandarin fruits. Postharvest Biology and Technology, v.13, n.3, p.255-261, 1998. 